products than is assumed in the Reactor Safety Study. Moreover, the non-existence of a threshold for radiation-induced cancer, on which some of the most extreme calculations of consequences are based, is by no means as secure as critics of nuclear energy assume.

The future of nuclear energy depends on keeping the core-melt frequency low enough; and, as the number of reactors grows, the core-melt probability per reactor will have to fall correspondingly. In this respect Ford and I agree. But where I see the establishment of the Nuclear Safety Analysis Center and of the Institute for Nuclear Power Operations (which now encompass more than 90 per cent of all the world's reactors outside the Soviet bloc) as an effective means of enhancing knowledge and thereby reducing the likelihood of accident, Ford remains sceptical. And where I see the spectre of bankruptcy as a very strong incentive for reactor operators to correct deficiencies that have been revealed by Probabilistic Risk Assessments of specific reactors, Ford seems to dismiss this incentive. Yet when Probabilistic Risk Assessment revealed that the auxiliary feedwater system of the Calvert Cliffs reactor lacked enough back-up, the Baltimore Gas and Electric Company, largely on its own initiative, installed an additional auxiliary feedwater train.

One of Daniel Ford's themes is that good men were so blinded by visions of a golden age based on their technology, their transuranic elements, as to ignore the faults of their technology. In short, that overweening ambition and misguided enthusiasm have led to actions that, in his view, have been profoundly irresponsible. But Daniel Ford, as well as his colleagues in the anti-nuclear movement, bear an equally heavy weight of responsibility. To be sure, he is moderate in his actual recommendations - upgrading the safety of existing plants, curtailing the operation of some of them located in heavily populated areas, and generally stepping backwards. But in presenting an indictment that is so one-sided, he adds powerful impetus to the popular and political forces that have already halted nuclear energy in several Western countries. Is he, as well as The New Yorker magazine, which first published The Cult of the Atom, prepared to accept the full consequences of a rejection of nuclear energy?

The anti-nuclear community, as exemplified by Daniel Ford, has not discovered a practical alternative to nuclear energy. Unless such an alternative is found, I believe future generations will regard the nuclear establishment as having acted more responsibly than those who would find their fulfilment in the elimination of our only practical inexhaustible energy source. $\square$

Alvin M. Weinberg is Director of the Institute for Energy Analysis of Oak Ridge Associated Universities, Tennessee. From 1955 to 1973 he was Director of Oak Ridge National Laboratory.

\section{In short, innovation in technology}

\section{Bruce Williams}

\section{A Short History of Twentieth-Century \\ Technology c. 1900-1950. \\ By Trevor l. Williams. \\ Oxford University Press: 1982. Pp.411. £12.50,\$25.}

THE LAST two volumes of the seven-volume History of Technology, published by Oxford University Press in 1978, dealt with changes in technology from about 1900 to 1950. This short history by one of the editors of that work, Dr Trevor Williams, deals with the same period and is designed "to give the general reader a broad conspectus of the way in which technology developed and a glimpse of the social, economic and political factors that influence the development"'

The book is well written, has excellent bibliographies at the end of each chapter, and includes many well-chosen illustrations. Explaining to the general reader the relevant science and engineering involved in, for example, nuclear weapons and power stations, antibiotics, selective weedkillers and insecticides, polymers, thermionic valves, transistors, computers and rockets is a formidable task which $\mathrm{Dr}$ Williams has managed most skilfully.

$\mathrm{He}$ is, however, less successful in providing a glimpse of the social, economic and political factors that influence the rates of change. In his introductory chapter he provides a sketch of the ways in which the spread of education in science and technology, the increases in Government support for R\&D and in industry-financed industrial $R \& D$, and changes in industrial organization contributed to higher rates of change. He also gives examples in several of his chapters of the ways in which - in the new environment - the interactions of "demand pull" and "technology push" stimulated change, but he could have provided a much more illuminating account had he paid closer attention to that distinction between invention and innovation which economists find so useful.

There are several references in the book to the influence of developments in technology on the way we live now, but - in striking contrast to the treatment of changes in technology itself - curiously few cross-references. For example, it is stated in Chapter 1 that "with the return of peace there seemed no limit to what science and technology could do for the benefit of mankind", though four chapters later there is a very good account of the development of the atom bomb, and in the penultimate chapter an account of military technology. The contrast between Longton in the Potteries in 1910 and 1970 , shown by the illustration on the dust cover, is an excellent example of how the environment can be influenced by changes in technology - in this case from coal-burning bottle kilns to electric and gas-fired ovens - and supporting legislation. Surprisingly, though, the only environmental issues dealt with in the chapter of public health are the improved technologies for storing and treating sewage, and for distributing water safe for drinking.

These limitations could be overcome in a second edition without a great increase in the size of the book. Nonetheless, if this first edition is judged on the basis of the author's intention - to provide a brief account of technological innovation and a glimpse of the social, economic and political factors that influenced it - that judgement should be very favourable. I certainly enjoyed the book and profited from reading it.

Sir Bruce Williams is the Director of The Technical Change Centre, London, and Visiting Professor at Imperial College, University of London.

\section{Immunoparasitology}

\section{anew}

\section{F.E.G. Cox}

Immunology of Parasitic Infections, 2nd Edn.

Edited by Sydney Cohen and Kenneth S. Warren.

Blackwell Scientific/C.V. Mosby: 1982. Pp.840. £48, \$99.50.

THE SIX years since the first edition of Immunology of Parasitic Infections was published have witnessed the emergence of immunoparasitology as a coherent discipline. It is no longer a subject which lags behind traditional immunology but now sets the pace itself.

The editors have faced the developments of those six years with courage and determination and the new edition is a completely different book from its forebear; few of the original chapters or authors appear in it. The section on immune responses to parasitic infections has been expanded from three chapters to six and coverage of immunodiagnosis has been reduced from ten chapters and incorporated into the relevant sections on specific infections, as has immunopathology which previously warranted four chapters.

The main section of the book now consists of fifteen chapters instead of ten. These deal with the more important parasitic diseases, this time including babesiosis and fascioliasis - which will make the book more useful for veterinarians and zoologists - and filariasis and giardiasis which were inadequately covered or omitted from the 